\title{
Effect of gamma ray on optical characteristics of (PMMA/PS) polymer blends
}

\author{
Mahasin F. Hadi Al-Kadhemy ${ }^{1}$ Asrar Abdulmunem Saeed ${ }^{1} \cdot$ Rana Ismael Khaleel $^{1}$. \\ Farah Jawad Kadhum Al-Nuaimi ${ }^{1}$
}

Received: 18 November 2016/Accepted: 25 June 2017/Published online: 11 July 2017

(c) The Author(s) 2017. This article is an open access publication

\begin{abstract}
Gamma ray effect has been worked out on PMMA/PS blends at different concentrations. The optical constants such as the absorption coefficient, refractive index are calculated, and optical energy gap (direct/indirect) has been studied before and after irradiation. Transmittance, absorbance, and reflectance spectra of pure and blends polymers are investigated.
\end{abstract}

Keywords Polymer blend P PMMA polymer · PS polymer · Gamma radiation - Optical properties

\section{Introduction}

The effect of radiation on polymeric materials is of great importance as it allows modifying and improving the physical properties of polymers. Irradiation of polymeric materials with gamma rays, X-rays, accelerated electrons, and ion beams, for example, leads to the formation of reactive intermediates and free radicals which then lead to important reactions such as degradation or cross linking. These interactions have been controlled by the given amount of radiation dose [1]. Different polymers have different reactions affected by the dose of radiation, which are intrinsically related to the chemical structures of the polymers. Therefore, the properties of polymer such as the optical, electrical, mechanical, and chemical become modified [2].

Polymer blends can be broadly divided into three forms: (1) immiscible polymer blends; (2) compatible polymer

Mahasin F. Hadi Al-Kadhemy

drmahasinf@yahoo.com

1 Physics Department, College of Science, Al-Mustansiriyah Univ, Baghdad, Iraq blends; and (3) miscible polymer blends. Our research includes blends from the first kind that is a heterogeneous polymer blends, this is so far the most populous group, and if the blend is made of two polymers, two glass transition temperatures will be observed [3].

Polymer blends are widely used materials in the new polymer industry because of their wider range of properties as compared to the individual polymers [4]. Where the materials mixed chemically and physically with each other to produce a new functional properties, as a result, polymer blend finds application in numerous fields such as adhesion, glutinous stability, design of composite, and compatible vital materials.

Optical properties of blends of PMMA compared with other polymers have been measured by many researches [5, 6]. PMMA and PS are known polymers and their mechanical, chemical, and other properties have been investigated [7]. The PMMA have a good compatible nature with the other polymers; therefore, this study done to show the effect of various ratios from PMMA with PS polymer as a thin-film blends and its effect on some important optical parameters such as absorbance, refractive index, reflectivity, absorbance coefficient, dielectric constant, and calculate energy gap. In addition, the main goal of this project is to study the effect of gamma irradiation on these properties.

\section{Experimental work}

Polystyrene (PS) which is the form of granules and polymethyl methacrylate (PMMA) is manufactured by the company (ICI). The preparation method is casting method [8]. The polymers separately dissolved in tetrahydrofuran (THF) with $99.998 \%$ purity. Different percentages (0/100, $20 / 80,50 / 50,80 / 20$, and $100 / 0 \%$ ) from the two polymers are mixed very well at magnetic stirrer and poured into the 
clean glass Petri dish and left for $24 \mathrm{~h}$ to obtain homogenous films.

The measurements of absorbance and transmittance spectra in the wavelength range (200-1100) nm were carried out using a UV-VIS (T70/T80 Spectrophotometer).

Cs-137 served as the gamma irradiation source, the film samples were placed simultaneously at the centre of the chamber surrounded for radiation equilibrium purposes, and samples were irradiated with (200 rad) dose, for $48 \mathrm{~h}$ at room temperature.

Film thicknesses were calculated from digital micrometer type (Tesha) $(0.001) \mathrm{mm}$ that are $(0.11-0.5) \mathrm{mm}$ for samples.

\section{The theory}

The absorption coefficients $(\alpha)$ have been estimated by [9]:

$\alpha=\frac{(2.303 \times A)}{t}$,

where $(t)$ is the thin-film thickness and $(A)$ is the absorbance. The Tauc relation for dependence of absorbance on photon energy applies [10]

$\alpha(v)=\frac{B(h v-E)}{h v}$.

The refractive index $(n)$ that is the ratio of the velocity of the light in vacuum to that of the specimen calculated by:

$n=\frac{1+R^{1 / 2}}{1-R^{1 / 2}}$.

The extinction coefficient $(K)$ is the extinction occurring to the electromagnetic wave inside the material:

$K=\frac{\alpha \lambda}{4 \pi}$.
The dielectric constant of compound $(\varepsilon)$ is divided into two parts real $\left(\varepsilon_{\mathrm{r}}\right)$ and imaginary $\left(\varepsilon_{\mathrm{i}}\right)$ that are calculated by this Eq. [11]:

$\varepsilon_{\mathrm{r}}=n^{2}-k^{2}$

$\varepsilon_{\mathrm{i}}=2 n k$.

The dielectric constant $(\varepsilon)$ can be calculated by

$\varepsilon=\varepsilon_{\mathrm{r}}+i \varepsilon_{\mathrm{i}}$.

The relation for dependence of absorbance on photon energy applies [12]

$\alpha(v)=\frac{B\left(h v-E_{\mathrm{g}}^{\mathrm{opt}}\right)^{x}}{h v}$,

where $\alpha$ is the absorption coefficient, $E_{\mathrm{g}}^{\text {opt }}$ represents the optical energy gap, $h$ is the plank's constant, $v$ is the frequency, and $x$ is the parameter that gives the type of electron transition, and it was observed that two distinct linear relations were found for $x=1 / 2$ (direct transition) and $x=2$ (indirect transition), corresponding to different interband absorption processes [13, 14] and factor $B$ depends on the transition probability and can be assumed to be constant within the optical frequency range.

\section{Results and discussion}

Figure 1a, b reveals a high absorption probability below 250 and $290 \mathrm{~nm}$ for PMMA and PS, respectively, and there is sudden decrease in the absorption values. The irradiated samples responded to the doses exposed by an increase in the absorbance with different concentrations of the blend, and the maximum absorbance was at wavelength $300 \mathrm{~nm}$ before irradiation and $350 \mathrm{~nm}$ after irradiation. The $50 \%$ PMMA/50\% PS blend showed the higher absorption values in comparison with other concentrations.

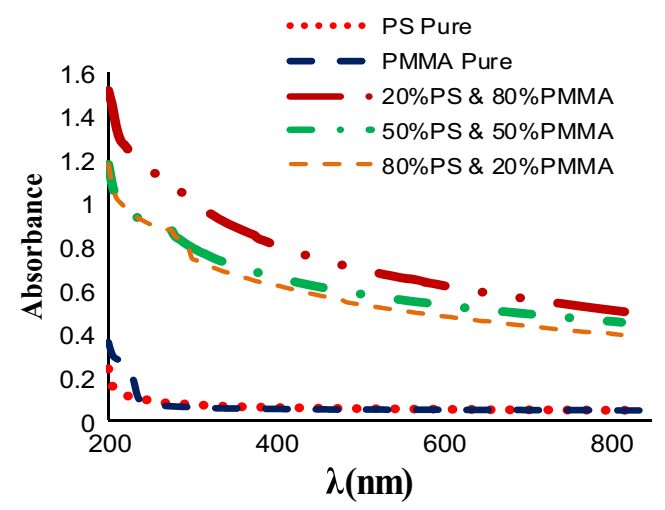

(a)

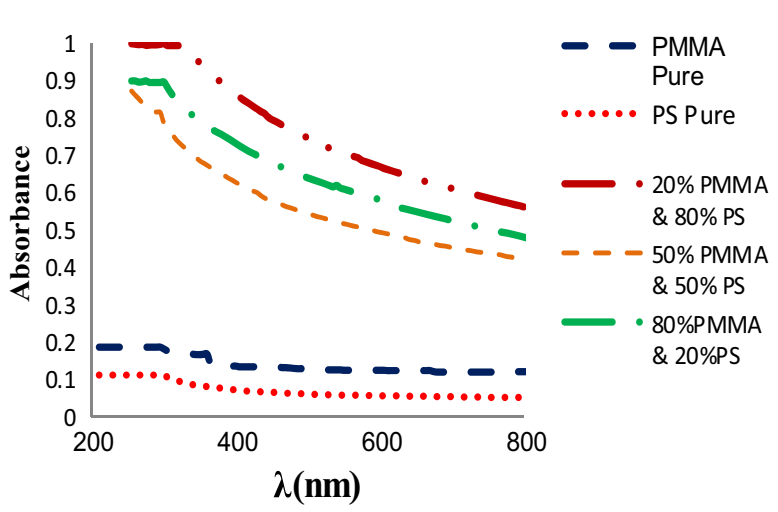

(b)

Fig. 1 a Absorbance as a function of wavelength before irradiation. b Absorbance as a function of wavelength after irradiation 


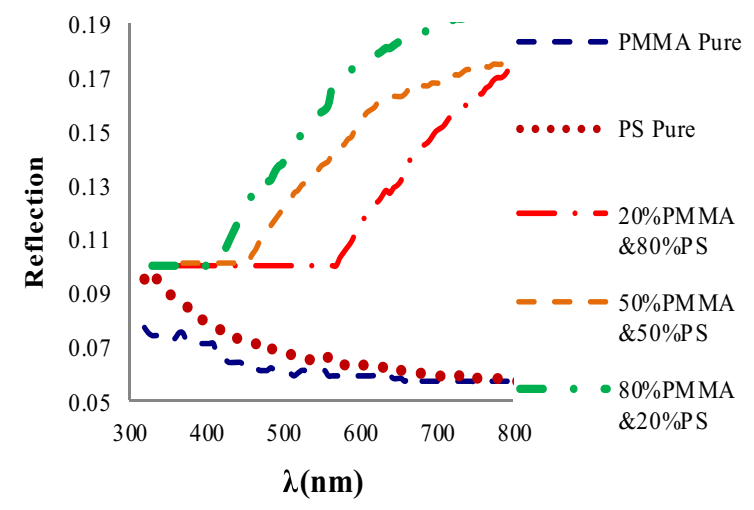

(a)

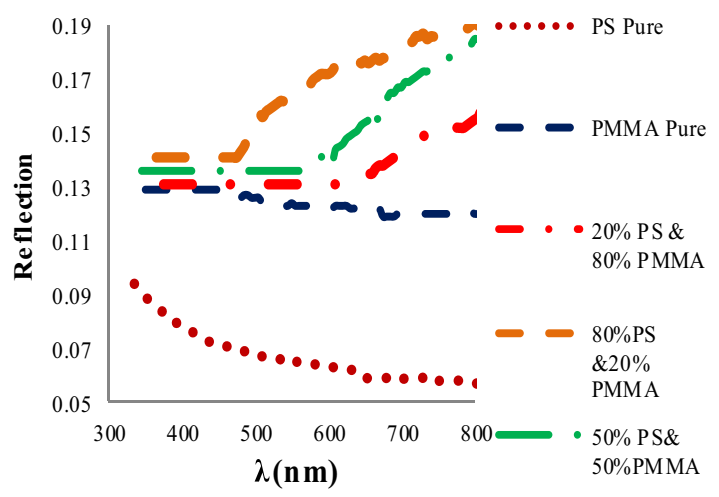

(b)

Fig. 2 a Reflection as a function of wavelength before irradiation. b Reflection as a function of wavelength after irradiation

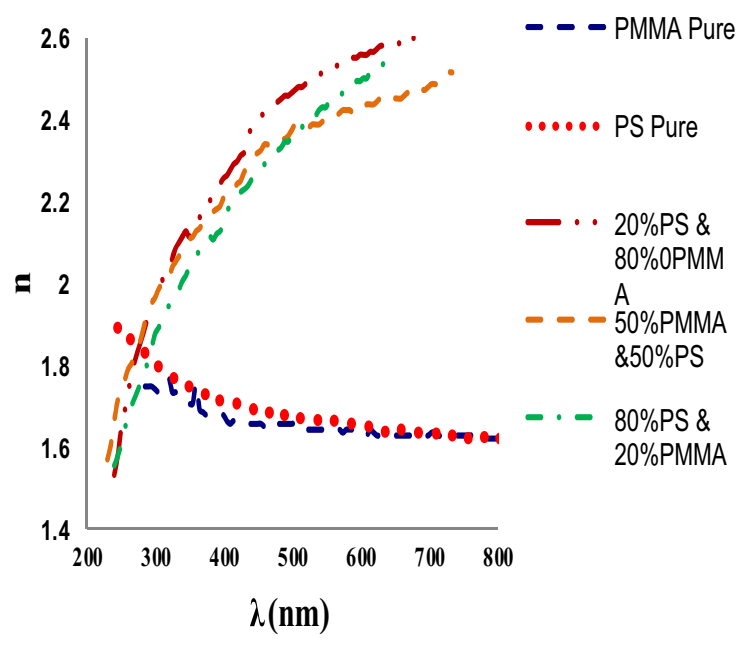

(a)

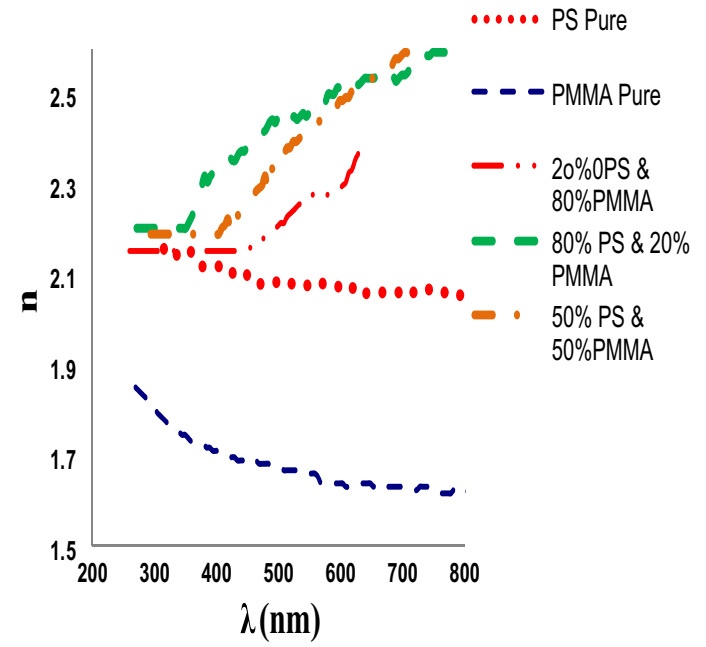

(b)

Fig. 3 a Refractive index as a function of wavelength before irradiation. b Refractive index as a function of wavelength after irradiation

A sudden decrease in the absorption values in the visible region, the best absorption, was for the 20\% PMMA and $80 \%$ PS. This may be attributed to the decrease in the levels at the energy band by increasing the PS contrition, and these results are in good agreement with other researchers $[15,16]$.

Figure 2a shows that the reflection $(R)$ against wavelength $(\lambda)$ of PMMA/PS thin films before and after irradiation, and it shows the increase in the reflectance with increase PMMA concentration before and after irradiation of gamma ray. The reflectance spectra will be used in the determination of refractive index and dielectric constant.

The reflective index $(n)$ spectra, before and after irradiation for homopolymer (PMMA, PS), and the blends in different concentrations are illustrated in Fig. $3 a, b$, the refractive index increased with increasing the wavelength value towards higher values of wavelengths $(200-800) \mathrm{nm}$, and reached a nearly constant value, and the effect of irradiation clearly be seen in figures. The refractive index for pure PS and PMMA before irradiation was 1.8 in $200 \mathrm{~nm}$ and after irradiation became 1.9 for PMMA pure and 2.2 for PS pure.

Figure $4 a, b$ shows the effect of the irradiation on the extinction coefficient $(K)$, the best effect was for $80 \%$ PMMA and 20\% PS for both before and after irradiation, and polymer blends do not always reflect similar information to that of individual. Thus, behavior was attributed to immiscibility.

The absorption coefficient calculated from Eq. (1) is illustrated in Fig. 5a, b for all samples before and after gamma irradiation. Their values do not exceed 1000 and $300 \mathrm{~cm}^{-1}$ before and after irradiation, respectively.

The real and imaginary parts of dielectric constant are calculated from Eqs. (4) and (5), respectively. They 


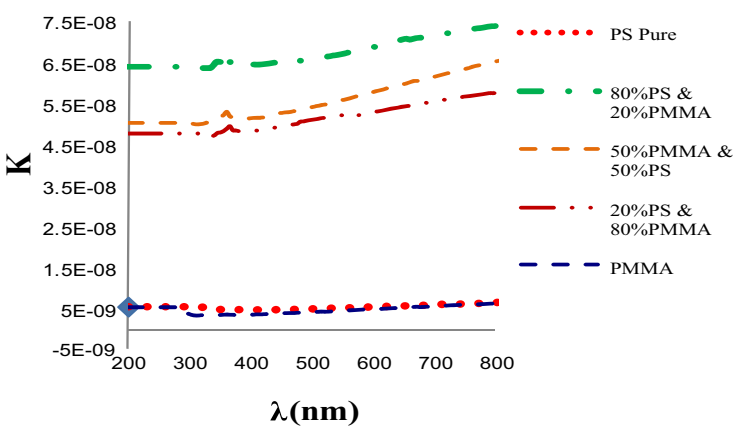

(a)

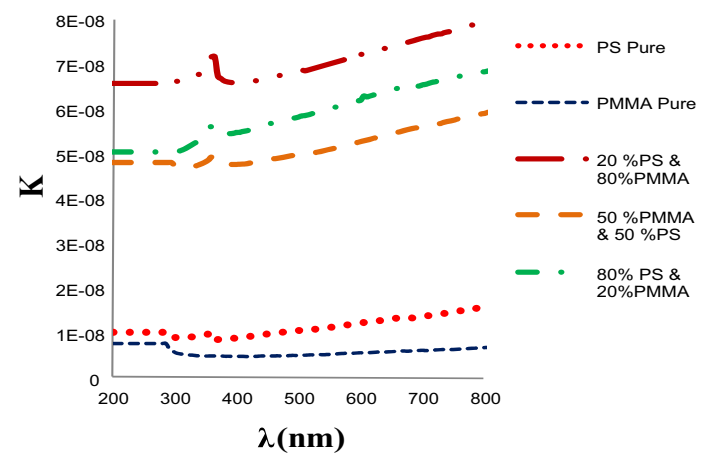

(b)

Fig. 4 a Extinction coefficient as a function of wavelength before irradiation. b Extinction coefficient as a function of wavelength after irradiation

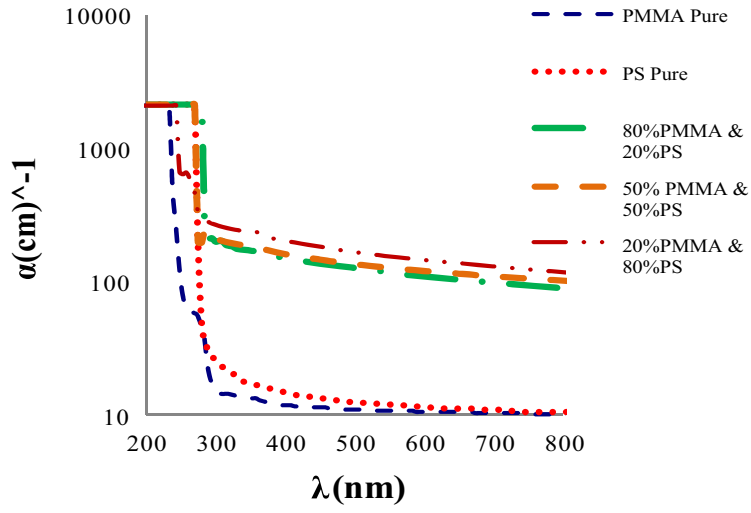

(a)

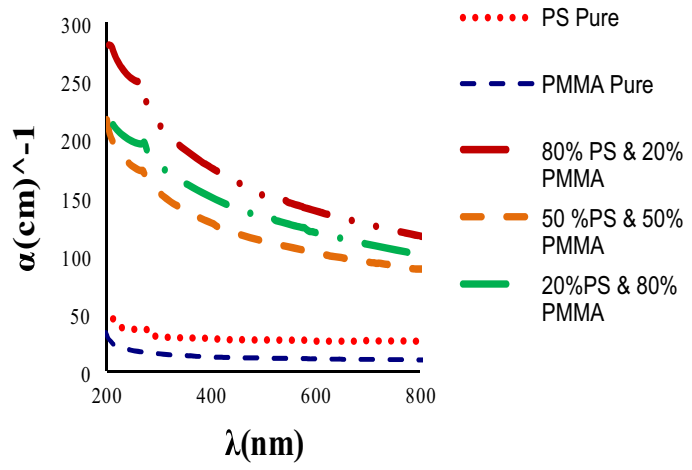

(b)

Fig. 5 a Absorption coefficient as a function of wavelength before irradiation. b Absorption coefficient as a function of wavelength after irradiation

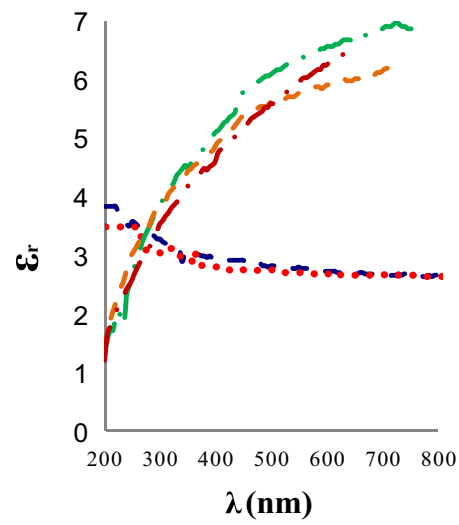

(a)

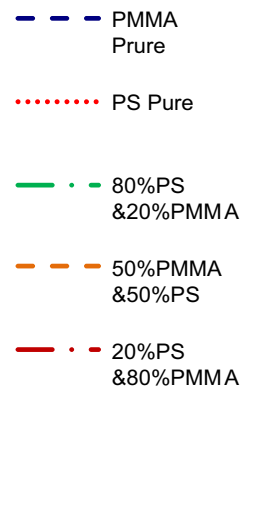

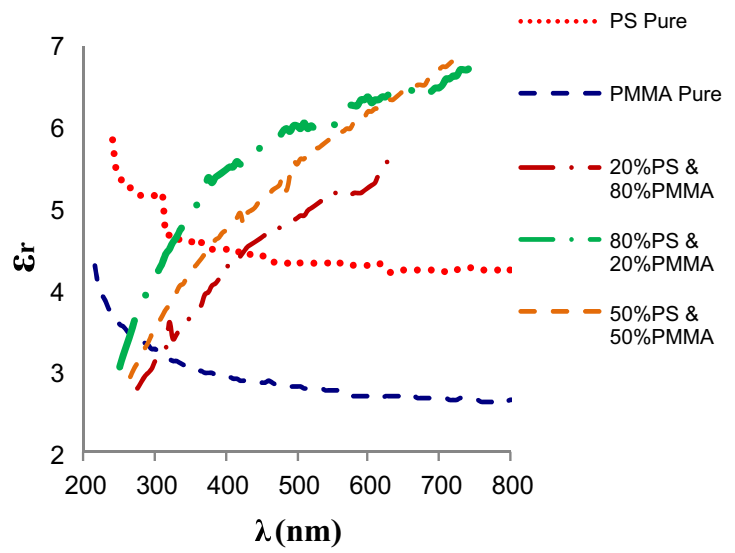

(b)

Fig. 6 a Real part of dielectric constant as a function of wavelength before irradiation. b Real part of dielectric constant as a function of wavelength after irradiation

have the same behavior curves, but the values of real part are higher than those of the imaginary part, and Figs. $6 a, b$ and $7 a, b$ show the real and imaginary parts of the dielectric constant increased with increasing wavelength, its agreement with other research [17, 18], respectively. 


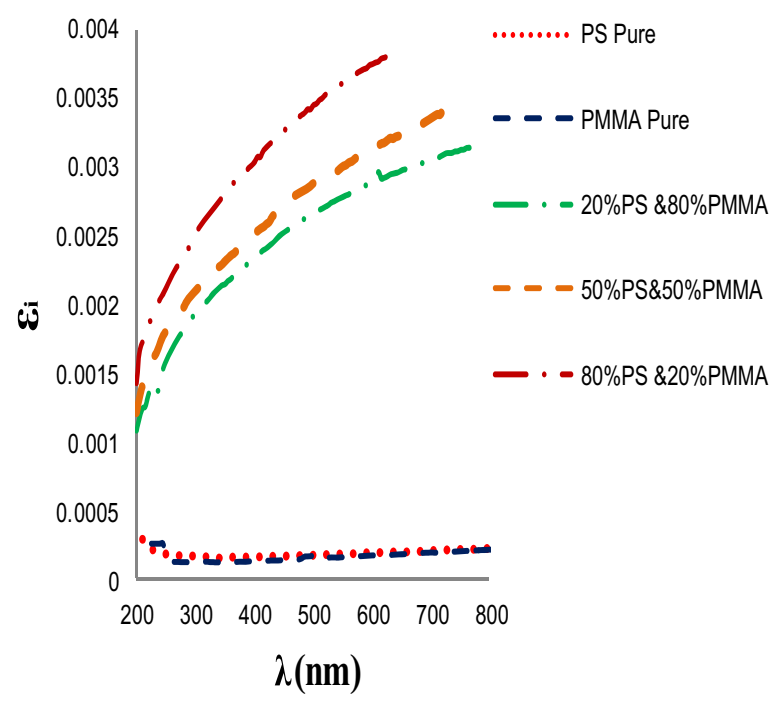

(a)

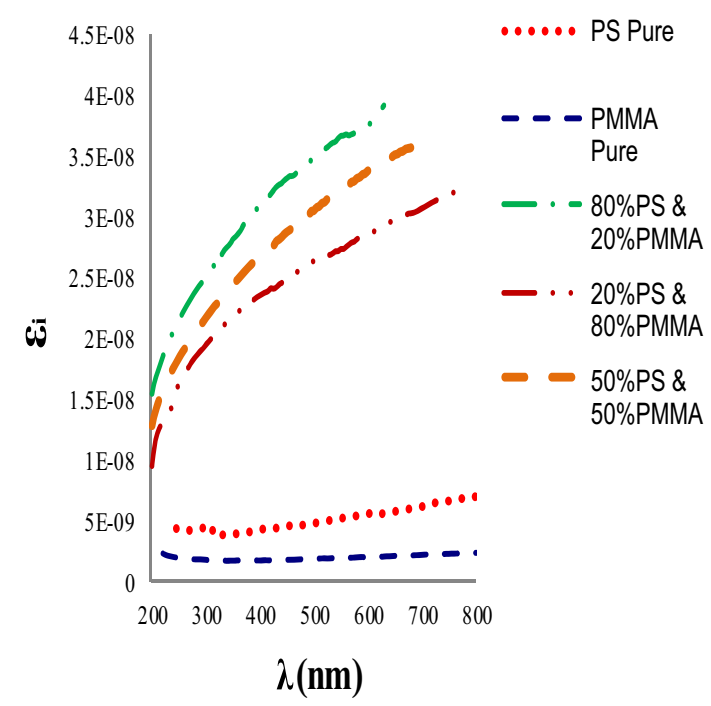

(b)

Fig. 7 a Imaginary part of dielectric constant as a function of wavelength before irradiation. b Imaginary part of dielectric constant as a function of wavelength after irradiation

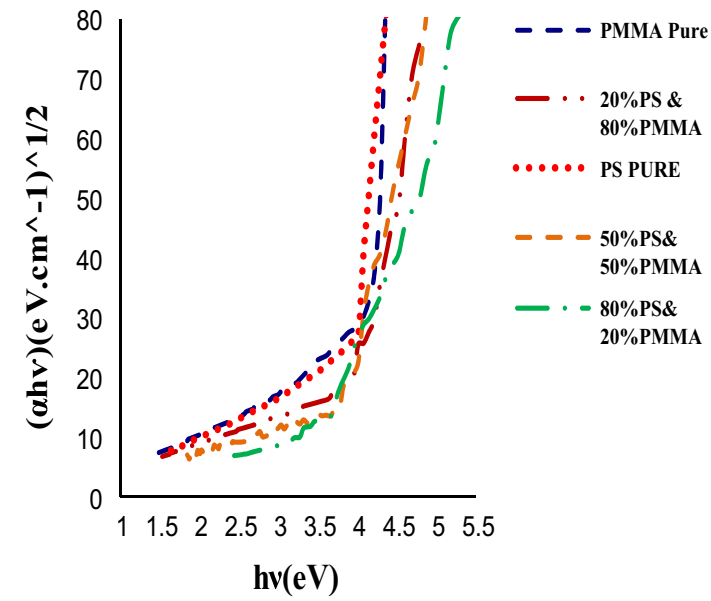

(a)

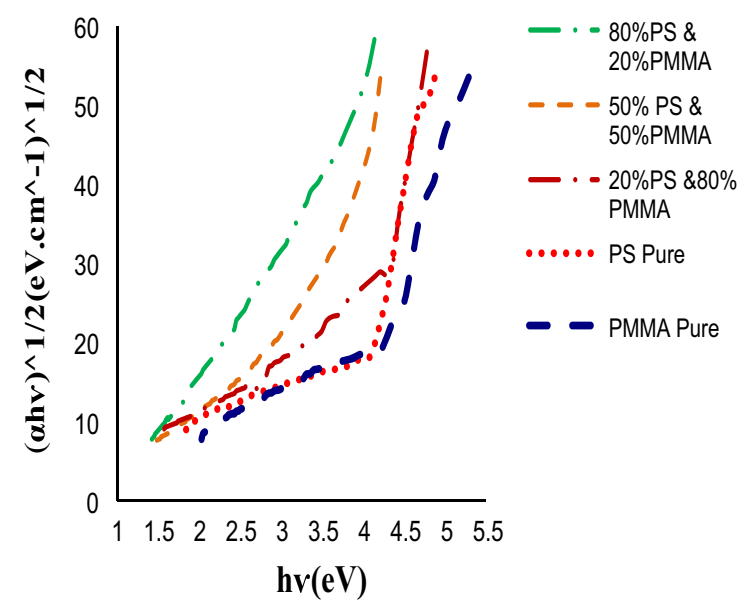

(b)

Fig. $8 \mathbf{a}(\alpha h v)^{1 / 2}$ as a function of photon energy before irradiation. $\mathbf{b}(\alpha h v)^{1 / 2}$ as a function of photon energy after irradiation

Figures $8 \mathrm{a}, \mathrm{b}$ and $9 \mathrm{a}, \mathrm{b}$ show the energy gap direct and indirect before and after irradiation and the position of the absorption edge for homopolymer and binary blends at different concentrations from the cutoff on the energy axis concludes that the linear part of the curves to zero absorption value gives the direct and indirect bandgaps. The linear part was best fitted with $(r=1 / 2$, $r=2)$, it is found that $\left(E_{\mathrm{g}}^{\mathrm{opt}}\right)$ is compositional dependence, the direct and indirect bandgaps are influenced by irradiation of gamma ray, where the values are increased after irradiation with change in the rates of blending, and Figs. 10 and 11 show the changing before and after irradiation.
The various optical properties obtained for different samples before and after irradiation are listed in Tables 1 and 2, and it shows the values of optical constants changing after exposure to radiation of gamma ray with the different ratio percentages of the blends.

\section{Conclusion}

UV-VIS spectrophotometric studies optical properties for irradiated PMMA/PS blend films with different concentration ratios, the indirect bandgap is greater than the direct bandgap, the decrease in the energy bandgaps after 


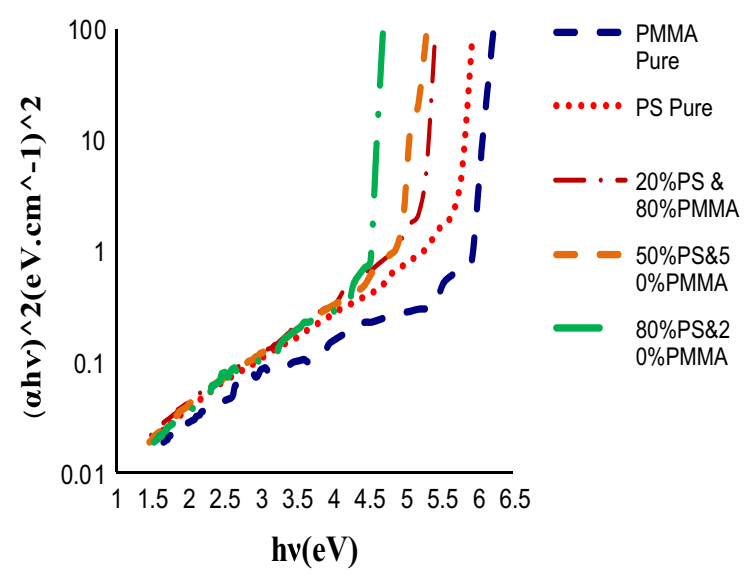

(a)

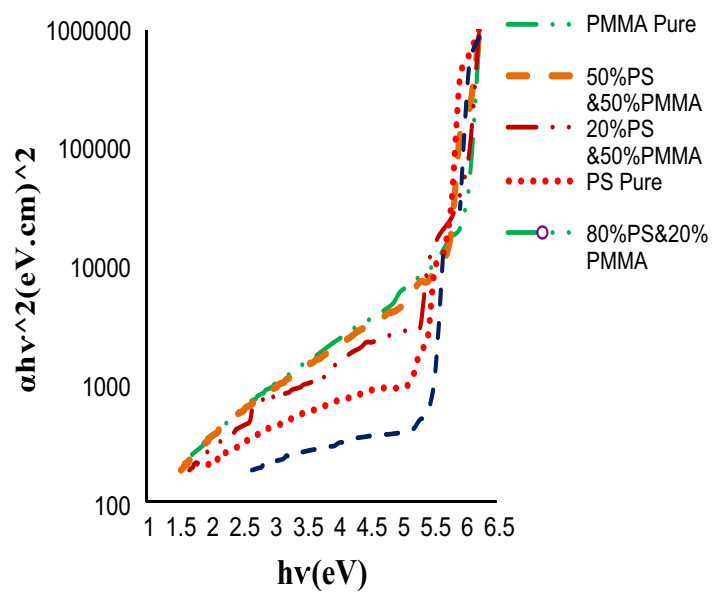

(b)

Fig. $9 \mathbf{a}(\alpha h v)^{2}$ as a function of photon energy before irradiation. $\mathbf{b}(\alpha h v)^{2}$ as a function of photon energy after irradiation

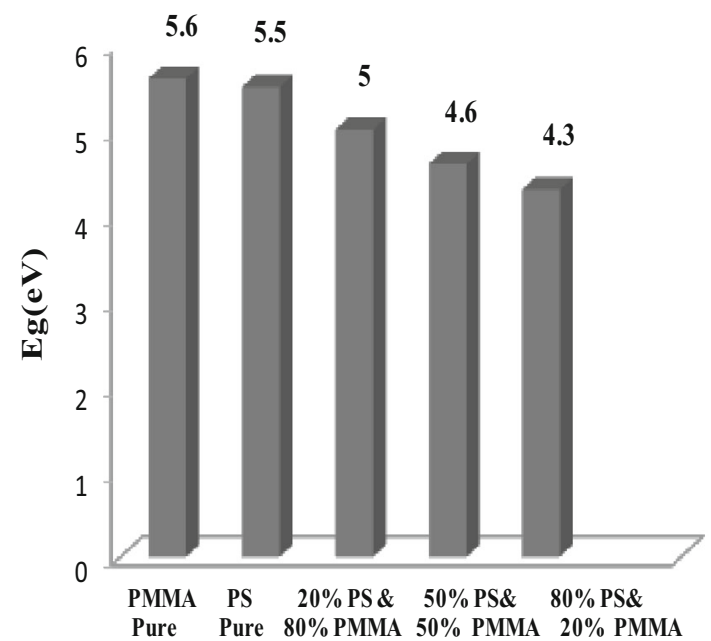

(a)

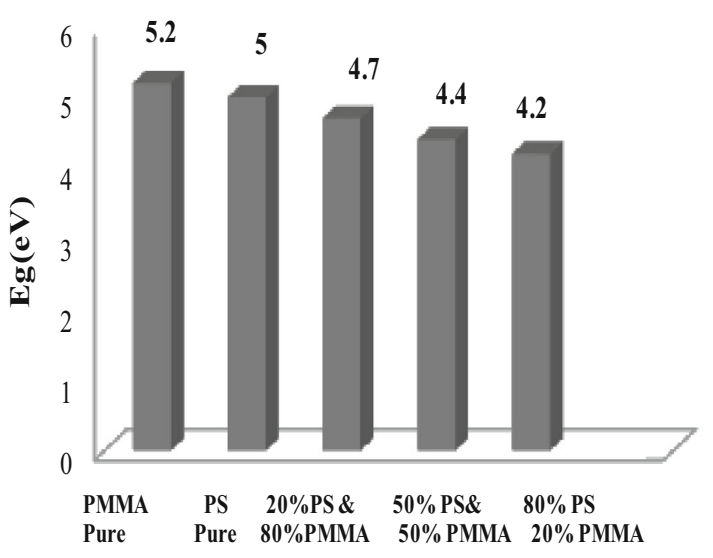

(b)

Fig. 10 a Indirect energy gap $(\alpha h v)^{2}$ values of PMMA/PS films with different ratios before irradiation. b Indirect energy gap $(\alpha h v)^{2}$ values of PMMA/PS films with different ratios after irradiation

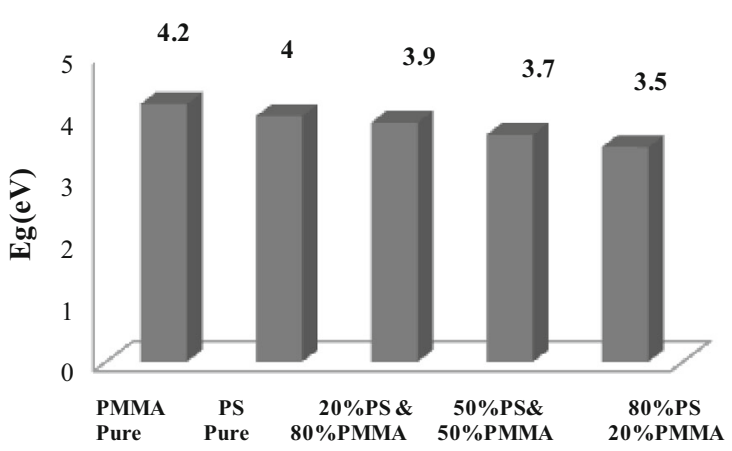

(a)

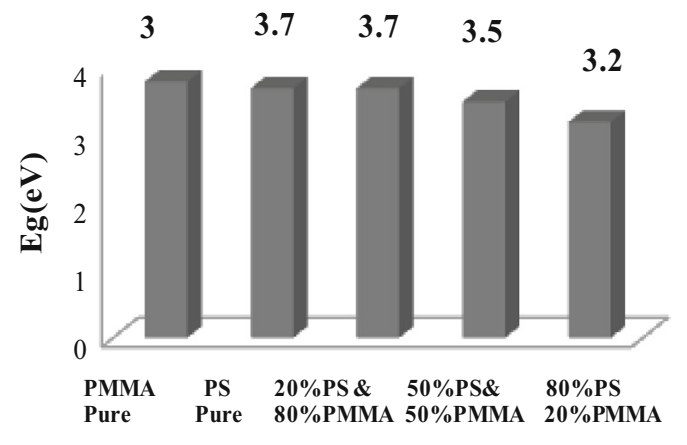

(b)

Fig. 11 a Indirect energy gap $(\alpha h v)^{1 / 2}$ values of PMMA/PS films with different ratios before irradiation. b Indirect energy gap $(\alpha h v)^{1 / 2}$ values of PMMA/PS films with different ratios after irradiation 
Table 1 Parameters of optical properties of polymer system before irradiation

\begin{tabular}{llllll}
\hline Polymer system & $\lambda_{\text {cut }}(\mathrm{nm})$ & $n$ & $K$ & $\varepsilon_{\mathrm{r}}$ & $\varepsilon_{\mathrm{i}}$ \\
\hline PMMA pure\% & 290 & 1.8 & 0.005 & 3.87 & 0.00048 \\
PS pure\% & 300 & 1.7 & 0.0056 & 3.99 & 0.0005 \\
20\% PS and 80\% PMMA & 350 & 2.1 & 0.00047 & 4.53 & 0.0016 \\
50\% PS and 50\% PMMA & 400 & 2.3 & 0.00052 & 5.75 & 0.0029 \\
80\% PS and 20\% PMMA & 600 & 2.5 & 0.00068 & 6.78 & 0.0036 \\
\hline
\end{tabular}

Table 2 Parameters of optical properties of polymer system after irradiation

\begin{tabular}{llllll}
\hline Polymer system & $\lambda(\mathrm{nm})$ & $n$ & $K$ & $\varepsilon_{\mathrm{r}}$ & $\varepsilon_{\mathrm{i}}$ \\
\hline PMMA\% & 290 & 1.85 & 0.00012 & 3.92 & 0.00049 \\
PS\% & 300 & 2.1 & 0.00015 & 4.91 & 0.0005 \\
20\% PMMA and 80\% PS & 350 & 2.2 & 0.00052 & 4.68 & 0.0025 \\
50\% PMMA and 50\% PS & 400 & 2.4 & 0.00065 & 5.93 & 0.003 \\
80\% PMMA and 20\% PS & 600 & 2.6 & 0.0007 & 6.88 & 0.004 \\
\hline
\end{tabular}

irradiation with gamma ray may be attributed to an increase in rearranging in the molecules of the polymer blends when it is exposed to radiation, and the optical constants also affected by gamma ray as shown in tables, and each optical constants have changed value after irradiation.

Open Access This article is distributed under the terms of the Creative Commons Attribution 4.0 International License (http://crea tivecommons.org/licenses/by/4.0/), which permits unrestricted use, distribution, and reproduction in any medium, provided you give appropriate credit to the original author(s) and the source, provide a link to the Creative Commons license, and indicate if changes were made.

\section{References}

1. Makuuchi, K., Cheng, S.: Radiation processing of polymer materials and its industrial applications. Wiley, Hoboken, New Jersey (2012)

2. Swu, T., Pongener, C.A., Sinha, D., Sen Sarma, N.L.: Effect of gamma radiation on dielectric properties of polyacetate polymer. Pelagia Res. Lib. 4(3), 132-136 (2013)

3. Mittal, V.: Functional polymer blends. Routledge, Taylor \& Francis Group LLC (2012)

4. Ibrahim, B.A., Kadum, K.M.: Influene of polymer blending on mechanical and thermal properties. Mod. Appl. Sci. 4(9), 157-161 (2010)
5. Deshmukh, S.H., Burghate, D.K., Shilaskar, S.N., Chaudhari, G.N., Deshmukh, P.T.: Optical properties of polyaniline doped PVC-PMMA thin films. Indian J. Pure Appl. Phys. 46, 344-348 (2008)

6. Takahashi, S., Okada, H., Nobukawa, S.: Optical properties of polymer blends composed of PMMA/EVA. Eur. Polym. J. 48, 974-980 (2012)

7. Mark, J.E.: Polymer data hand Book. Oxford University Press Inc (1999)

8. AL-Kadhemy, M.F.H., AL-Jabry, A.N.A.: Optical properties and FWHM of methylene blue doped poly vinyl alcohol films. Int. J. Mater. Sci. Innov. (IJMSI) 2(6), 178-192 (2014)

9. Ziadan, K.M., Shswiand, A., AL-Alattar, A.L.: The electrochemical polymerization of conducting polymer PPy/PTFE. Iraqi J. Polym. 2(1), 95-102 (1998)

10. Balkanski, M.: Optical properties of solids, vol. 2. North-Holland Publishing Company, Amsterdam (1992)

11. Gutzler, R., Smulders, M., Lange, R.F.M.: The role of synthetic pharmaceutical polymer excipients in oral dosage forms-poly (ethylene oxide)-graft-poly (vinyl alcohol copolymer) in the tablet coating. Macromol. Symp. 225, 81-93 (2005)

12. Patel, G., Sureshkumar, M.B., Patel, P.: An optical characterization of PVA/PAM polymer blend. AIP Conf. Proc. 1349, 166-167 (2011)

13. Tauc, J., Grigorovici, R., Vanku, A.: Optical properties and electronic structures of amorphous Germanium. Phys. Stat. Sol. 15, 627 (1966)

14. Shahada, L., Kassem, M.E., Abdelkader, H.I., Hassan, H.M.: Optical and electrical properties of a new polymer. J. Appl. Polym. Sci. 65, 1653 (1997)

15. Hussain, H.A., Al-Hashimi, A.H.M., Nazai, F.Y.: The effect of gamma radiation on polyvinyl chloride and $\mathrm{CN}-85$. J. Basrah Res. 39(1), 112-124 (2013)

16. Mahasin, F., Al-Kadhemy, H., Abaas, W.H.: Absorption and fluorescence spectra of crystal violet doped PS and PMMA blend films. Fondazione Giorgio Ronchi 5, 735-744 (2012)

17. Al-Kadhemy, M.F.H., Hussein, I.F., Saeed, A.A.M.: Gamma irradiation effect on structural properties of copper doped polystyrene films. J. Appl. Chem. Sci. Int. 5(2), 83-92 (2016)

18. Alwan, T.J.: Gamma irradiation effect on the optical properties and refractive index dispersion of dye doped polystyrene films. Turk. J. Phys. 36, 377-384 (2012) 